no harm, but rather advantage, if they should; then, gentle oleaginous laxatives and enemata. Both the laxatives and enemata may have, if griping is severe, a few drops of the tincture of hyoscyamus or of opium added to them. In France, infusions of chicory, taraxacum, and lettuce, to which acetate of potass is added, are recommended.

In severer cases of bilious colic, a chillness, like the cold stage of fever, sometimes comes on. Against this, a hot bath is the best means, by which also the colicky pains are generally much alleviated.

2. Spasmodic, or nervous and flatulent colic.-These have many points of resemblance. If no signs of inflammation are present, they are to be treated by antispasmodic and carminative draughts and enemata, and by warm abdominal frictions. The following are the substances we must principally rely on : valerian, assafœtida, musk, castoreum, galbanum, belladonna, camphor, the aromatic waters and oils, as those of anis, fennel, pimento, carraway, \&c.

3. Scybalous colic.-In this variety, irritation of the mucous membrane of the bowel, even of a sub-inflammatory or inflammatory kind, may be caused by the prolonged contact of scybalæ; and either obstinate torpor of the gut, with constipation, may ensue, or, what is more to be dreaded, antiperistaltic action may commence, ending in dangerous or fatal ileus.

In this case, oleaginous laxatives, such as castor and olive oil, must be given, and that in a manner least likely to excite nausea; since thereby the tendency to anti-peristaltic action may be increased. Copious oily enemata, aromatised so as to excite the downward action of the bowels, should, at the same time, be assiduously employed. All drastic purgatives should be abstained from.

4. Lead or painter's colic.-The treatment of this disease, practised in a principal hospital of Paris, and which is often successful, is as follows:-

First day.-In the morning, a purgative enema is administered, consisting of the following various ingredients:-An aromatic electuary, containing scammony, thirty parts; jalap powder, four parts; senna, eight parts; syrup of buckthorn, thirty parts; boiling water, 125 parts. During the day, a tisane, made from cassia, sulphate of magnesia, and tartar emetic, is taken; and in the evening, an anodyne (?) enema of walnut oil and red wine, succeeded by a bol calmant, consisting of a drachm of theriaque (a senseless medley of almost every knownantispasmodic, tonic, and narcotic) and one grain of opium.

Second day.-This day commences with an emetic, con. sisting of two-thirds of a grain of tartar emetic in eight ounces of water, divided into two doses, and taken at the interval of an hour. In the course of the day, a sudorific tisane is drank, composed of a decoction of somewhat more than six ounces of rasped guaiac in one pound and a half of water; this being boiled down to half that quantity. In the evening, the "calming bolus" (see first day) is repeated.

Third day.-This day commences with a laxative sudorific tisane, consisting of an ounce of guaiac, half an ounce of sarsaparilla, a drachm or so of sassafias, the same of liquorice, half an ounce of senna, and so much water as to form, when boiled and strained, about half a pint of decoction. Soon after, a purgative potion is administered, consisting of an aromatic electuary, containing scammony, a drachm of jalap, two drachms of senna leaves, seven drachms of syrup of buckthorn, and one pound of boiling water. In the evening, the anodyne enema (see first day) and calming bolus (see ditto) are repeated.

Fourth day.-The same routine as the third.

Fifth day--During the day, the sudorific tisane is given, (see second day;) at four in the afternoon, the purgative enema, (see first day;) at six o'clock in the evening, the anodyne enema, (see ditto;) and at eight o'clock, the calming bolus, (see ditto,) are successively taken.

If the disease has not now yielded, the above whole series of treatment is repeated, (only the emetic solution is omitted,) and is continued until the abdominal pains are removed, and the patient goes regularly to stool.

It must be owned that the treatment now detailed is very methodical, and is a not unskilful melange of means calculated to stimulate the bowels, and to quiet them and relieve their spasmodic action alternately.

Alum and sulphuric acid also undoubtedly possess something like specific powers in the treatment of lead colic. Kapelex recommends from two to four or five drachms of alum to be dissolved in five ounces of a demulcent julep, and this to be taken in doses of a spoonful every hour. In Germany, this is much used, and is very successful. Dr. Copland states that he has uniformly succeeded by means of alum, which, however, he combines with camphor, cayenne pepper, and occasionally opium, and assists with oleaginous clysters. Gendrin recommends as a prophylactic to operatives engaged in lead mines or manufactories, a sulphuric acid, "lemonade," as he calls it, consisting of a drachm or two in a pint or more of water, sweetened so as to make it agreeable, and taken in quantities of twelve or sixteen ounces a day.

Besides the means now enumerated, elaterium, croton oil, calomel, and many things else, have been suggested and tried, in lead colic, with various results. We should, however, ourselves prefer the French treatment above detailed, or the aluminous treatment, which, it may be observed, " more certainly" (to use Dr. Copland's words) "opens the bowels than any other."

5. Vegetable, Poictou, or Devonshire colic.-This has been erroneously supposed to arise from the use of cider or acerb fruits. While, no doubt, such may be occasionally its origin, yet a colic precisely similar arises from totally different causes, as cold feet, \&c. We must combat it by hot fomentations and the conjoint use of mild laxatives, as castor oil, and opiates, or at least anodynes, and by oleaginous and anodyne enemata.

6. Meconial colic.-Castor or olive oil, with hot fomentationg to the abdomen, and mucilaginous injections, will usually speedily relieve this species. Indeed, half an ounce of syrup of the rose in the evening, and the same quantity in the morning, will often be all that is required. Sometimes, however, what Canstatt calls "deutero-pathic"* eclampsia is the result, demanding more active treatment. See the chapter entitled "Topographische Pathologie einzelner nerven und nervengebiete," in his Special Pathology and Therapeutics, pp. 370 et sequentes.

We do not refer to colic from unhealthy lactation in the mother or nurse, nor to colic which has passed, as every species of it occasionally does, into ileus, enteritis, and peritonitis. The treatment of these severe forms of disease was not contemplated in this series of papers. I may observe, that in The Larcet for March 25, 1843, Mr. Doughty, of Willam-street, Knightsbridge, reports a very serious case of ileus which I treated, and fortunately with success. On referring to the details of the case, I notice that the following were the principal points of the treatment:-columba and opium to arrest vomiting, an object of importance in all such cases; then a turpentine enema, with castor oil: on the following day, six ounces of quicksilver, (by mouth, and sixteen ounces of the tobacca enema, administered by Mr. Doughty; this caused syncope and cold sweat. On the following day, eight more ounces of quicksilver were given, and tobaccosmoke to the extent of five or six whiffs, on that, and again on the following day, by Mr. Doughty. Lastly, an assafoetida enema. "After the latter," writes Mr. Doughty, "we began to have copious stools, and the whole of the mercury passed."

I may observe, that before I was called to this case, stercoraceous vomiting had decidedly set in. My object in ordering the tobacco infusion and smoke enemata was to favour the reduction of any obscure hernia or muscular spasm of the bowel which might exist. I also directed that the attendants of the girl should, after she had taken the crude mercury, frequently raise her up in bed, (she was too feeble to raise herself, to alter her position from one side to the other, from the back to the belly, and vice versâ, with the view of favouring the gravitation of the mercury to the lower bowels. The issue of this case was extremely gratifying to me, inasmuch as I had despaired of a successful one. Had it proved unfavour. able, I should now, at least, perhaps have been disposed to blame some parts of the treatment as too energetic. How ever, the desperate aspect of things appeared to justify a prudent rashness, and as the issue was fortunate, I am not called upon, on this occasion at least, to practise the duty of self-stricture.

Bentinck-street, Manchester-square.

\section{ON THE CAUSES, SYMPTOMS, AND TREATMENT OF UTERINE HYDATIDS. WITH CASES.}

By CHARLES EDWARDS, M.D., M.R.C.S.F., Cheltenham.

I BEG to submit the subjoined remarks on uterine hydatids, accompanied by a case illustrative of the causes, symptoms, and treatment of a morbid condition or degeneration, much disputed as to its origin, and of so comparatively rare occurrence as to render its records most valuable and interesting.

* This is, of course, secondary, as contradistinguished from idiopathic eclampsia. 
With such authorities as Baudelocque, Voigtel, Desormeaux, Velpeau, and especially Madame Boivin and Dr. Montgomery, I believe uterine hydatids to be always the result of sexual intercourse. The argument from analogy against this view has been clearly answered by Dr. Mnntgomery, and is perhaps needless to detail to persons familiar with the subject of this paper.

S. A - residing in Sydney-street, aged forty-two, of bilions temperament, but of active habits, and healthy, states as follows:- She is always regular as to the catamenia, except during utero-gestation and suckling; has had six children, now living; has but once suffered abortion, and that twelve years ago. After weaning her last child, which she suckled till eighteen months old, the menses immediately reappeared, and continued regular for three months - the usual period of her former conceptions after weaning : they now ceased.

At the expiration of three months from their cessation, there succeeded a daily stillicidium of blood, generally, but not invariably, black; being, at length, in gushes of ordinary hæmorrhage after every slight exertion, and these constantly attended with foreing pains like those of parturition.

The concomitant symptoms were now constant nausea, vomiting after the most simple food-gruel, tea, \&c., and, in consequence, great emaciation, pain at scrobiculus cordis, and in the bowels. As to her appearance, the breasts and abdomen were enlarged, but, she thought, not proportionately to their development at the same stage of her former pregnancies. The bulk of abdomen "seemed to lie very high up." The usual umbilical prominence had also lately occurred. This brings us nearly to the end of six months, the three last of which she designated a continned labour and flooding, and in the three last weeks of which only she had sought medical advice at the disperisary, at the end of which time she was thought so much better by the medical officer as to be dismissed cured.

This temporary respite was, however, in a few hours, succeeded by still more violent and regular labour pains, and severe flooding, under which circumstances she first applied to me for advice.

At the expiration of about twelve hours of yegular pains and hæmorrhage, about a wash-hand basonful of hydatids were discharged, adhering like an immense cluster of grapes to a bloody, spongy substance, resembling a degenerated pla. centa, which being macerated and cut into exhibited an aggregate of hydatids embedded in its substance. I could detect no investing membrane nor portion of a fotus.

The pains and hremorrhage now subsided, but in a few hours returned, when an almost equal quantity of hydatids were discharged, which last mass, unhappily, I had not an opportunity of examining, it having been inconsiderately removed ly the attendants, who supposed that having reserved the first I would not require to examine further. A discharge, quite unlistinguishable from lochia, followed, but no secretion of milk.

So far as the case detailed is concerned, I think, by reviewing it carefully, little doubt can be entertained as to how the hydatid disease was here occasioned. The female was married, and so predisposed to the exciting cause; regular in the menses, except when pregnant or suckling; and the interval between the birth of her last child and the suppression of the menses after weaning, corresponded to her former enceptions in equi-distance.

As to the symptoms-this case presents strikingly interesting differences from most on record. Sir C. M. Clarke considers "the occasional and sudden discharge of an almost colourless and inodorous watery fluid a most constant, indeed, a diagnostic symptom." Such discharges were entirely absent in this case, which was remarkable for the hæmorrhage, as it were, of a prolonged abortion. I can find only two cases on record of this repeated and prolonged hæmorrhage--one by Mr. Watson, in the Philosophical Transactions, the other illustrated in Cruveilhier's "Pathology of Anatomy," of which, however, I believe no clear exposition has yet been given by authors.

In my opinion, the presence of these hæmorrhages is evidently determined by the place of adherence of the spongy or hydatid mass near the os uteri, acting, in fact, as that of a placenta prævia; whereas, in cases of watery discharges, the attachment is more remote from the os uteri, and vesicles not immediately attached are occasionally burst, thus giving rise to them so frequently; the case of the hæmorrhagic discharges being evidently thus seen to be most rare, as the determining site of adhesion is most abnormal and uncommon.

With respect to diagnosis, I think, with Madame Boivin, that ballottement is the best, and should always be essayed for pregnancy in suspicious cases; and I would regard any case of protracted hæmorrhage, with uterine pains, as sadly overlooked, were no vaginal examination instituted. Should the case be suficiciently advanced, the stethoscope may be appealed to.

After death, when concealment or inadvertent removal of the mass has occurred, I would look for the limited placental mark, (as hydatids have a wider adhesion, and a corpus luteum, as confirmatory, the latter of pregnancy, the former of delivery. Should, however, a hydatid mass be presented to me, the presence of a fotus, or part of the ovum, would of course decide the point of impregnation at once; but not inversely, I believe; yet, with Dr. Montgomery, if acting as a medical jurist, should $I$ find no trace of either, $I$ would give the patient the benefit of the doubt-(if she required the charity) shadowy indeed - their absence perhaps not being real, but inferred, (as I would explain further than he has done,) from the occasional impossibility of finding them.

In addition to the suggestion of Dr. Davis, that hydatids may be the result of conceptions of antecedent dates, I would name two other causes of failure, in proving cotemporaneous gestation, hitherto, I believe, unnoticed-viz., 1st, a perfect or advanced degeneration, (that which was most probably a placenta in my case appearing so;) or, 2ndly, as hydatids are discharged frequently at intervals, and in separate masses, the very part which may happen to contain traces of the ovum or fœtus may be removed by design or indifference, (the second lot was thus carelessly thrown away in my case,) and so the examiner may fail to find what really existed.

To these views of hydatid etiology, it has been triumphantly objected, that the disease has coèxisted with a hymen. My reply to Mr. Andrews is perhaps uncharitable - viz., hymens are sometimes lucky; pregnancy has also coëxisted with the same. Vide Ramsbotham's cases and others.

Do these etiological views derive confirmation from coincidence with the patient's feelings? : Dr. Montgomery argues thus: "In every instance under our inspection, \&c., the women supposed themselves with child." My patient quite doubted her being so situated: I speak of her feelings, for this doubt arose from the presence of the ordinary tronblesome sympathetic effects now present, and really confirmatory, but to which she was unused on former occasions.

As to the time at which a ceded pregnancy is degenerating -is this indicated by any peculiar symptoms? Professor Burns says yes: "the mammse become flaccid, and the sympathetic effects of pregnancy cease." In my case, the breasts, though never much distended, did not become flaccid, and the vomiting and other sympathies were most urgent during the degeneration. The black stillicidium was here the first index.

The first discharge of blood commenced, in the majority of Madame Boivin's cases, at three months. She does not state how long they lasted. My case coincided with this period, but was remarkable in having hæmorrhage protracted to the sixth month.

Finally, with respect to the treatment, I place most confidence in the tincture of ergot, with sulphuric acid, and compound spirit of sulphuric ether. By these means I had no need of introducing the hand to detach or remove hydatids, or excite uterine contraction; manipulations " which must be done cautiously, and only when hremorrhage, or some other urgent symptom, occurs."-BuRns.

My case had been sufficiently hæmorrhagic, but I believe that the plug, till the os uteri is sufficiently dilated, conjointly with the ergot, will effectually control all hæmorrhage, whether intermediate or subsequent to the final expulsion of the hydatid masses; which latter is generally most alarming, from the extent of uterine surface from which they have been detached.

Grosvenor-street, Cheltenham, Feb. 1847.

\section{ON THE TREATMENT OF STRICTURE OF THE URETHRA BY HYDRAULIC DILATATION.}

\section{BY JOHN GOODMAN, EsQ., M.R.C.S.E., Broughton,} Manchester.

An individual from the country applied to me, a few days ago, with complete retention of urine, owing to a stricture just in front of the bulb of the urethra, from which he had suffered for a considerable perion. A bout two months before, an instrument had been passed, by a surgeon in the country, with considerable difficulty, which he stated to be about the size of a small catgut bougie, and he had since that time totally neglected all remedial measures, and had usually mic- 